\title{
Systematic review of the economic aspects of nonadherence to antipsychotic medication in patients with schizophrenia
}

This article was published in the following Dove Press journal:

Patient Preference and Adherence

3 April 2013

Number of times this article has been viewed

\author{
Tatiana Dilla \\ Antonio Ciudad \\ María Álvarez \\ Department of Clinical Research and \\ Development, Lilly, S.A. Alcobendas, \\ Spain
}

\begin{abstract}
Purpose: There is strong evidence supporting the link between nonadherence to antipsychotic medication and relapse of schizophrenia. However, less obvious are the economic consequences of nonadherence. The systematic review reported here evaluated the economic aspects of nonadherence to antipsychotic medication.
\end{abstract}

Methods: A systematic review of scientific papers in the PubMed MEDLINE, Embase, PsychINFO, BIOSIS, and Evidence-Based Medicine Reviews databases was undertaken. Studies that measured adherence to antipsychotic medication and that provided comparative information on health care costs were included.

Results: Eight studies met the inclusion criteria. All were observational. Despite the differences between the studies in terms of design, adherence measures, and cost components analyzed, the results of this systematic review indicate that nonadherence to antipsychotic medication is associated with increased hospitalization rates and resource utilization, resulting in increased direct health care costs.

Conclusion: Nonadherence to antipsychotic medication results in poor health and economic outcomes; therefore, the authors suggest endorsing interventions aimed at improving adherence because they can improve patient health without substantially increasing costs.

Keywords: adherence, costs, observational study, hospitalization rates, resource utilization

\section{Introduction}

According to the widely accepted World Health Organization general definition, "therapeutic adherence" is "the extent to which a person's behavior corresponds with agreed recommendations from a health care provider." Adherence to antipsychotic medication is essential to improve outcomes in most patients with schizophrenia. ${ }^{2}$ However, nonadherence to long-term therapy is common, and it is particularly problematic in this condition. ${ }^{3,4} \mathrm{~A}$ variety of factors can affect adherence in schizophrenia. Authors have categorized such factors in several ways, but commonly arrange them in terms of their relation to the patient, his/her relationship with health care providers and caregivers, the medication, the environment, and some features of the service delivery system. ${ }^{3,4}$ Difficulties arise when measuring adherence. Practicing psychiatrists frequently have trouble acquiring an accurate measure of their patients' adherence level. ${ }^{5}$ Several methods have been used to this end, including both subjective (patient self-, caregiver, or physician report) and objective (pill counts, pharmacy records, electronic monitoring, or plasma concentrations). However, all are proxy measures of adherence, and none is devoid of significant limitations. ${ }^{6,7}$
Correspondence: Tatiana Dilla Health Outcomes Research Unit, Lilly, S.A., Avenida de la Industria, 30, E-28I08 Alcobendas, Spain Tel +34916235334 Fax +34 91 6633471 Email dilla_tatiana@lilly.com 
Antipsychotic nonadherence is more than a conceptual problem. It has a very negative impact on patients and society as a whole. ${ }^{8}$ There is strong epidemiologic evidence that indicates nonadherence significantly increases the risk of relapse $\mathrm{e}^{9-12}$ and is associated with impaired functional outcomes..$^{13}$ Also, adherence issues make it particularly difficult for the psychiatrist to assess treatment response and make appropriate adjustments to therapy, ${ }^{5}$ not to mention the long-term consequences it may have by precluding patients from benefiting from prolonged periods of symptomatic remission..$^{14,15}$

Schizophrenia is a devastating mental illness that carries a significant economic burden. ${ }^{16,17}$ Although many studies have addressed the clinical consequences of nonadherence in schizophrenia, utilization of health care resources and costs have received little attention. Nonadherence to antipsychotic medication also has a relevant socioeconomic facet, because it is likely to result in an increase in the frequency of relapse, more severe symptoms, and longer hospital stays, which may lead to increased utilization of health care resources ${ }^{18}$ and costs. ${ }^{19,20}$ In particular, relapse has been consistently noted to be an important predictor of subsequent relapse and treatment costs. ${ }^{21}$ Although relapse has been commonly associated with elevated costs of inpatient treatment, other cost components are also higher in patients who relapse than in those who do not. ${ }^{21}$

The current environment, dominated by attempts to curtail health care cost escalation, demands information about the economic consequences of nonadherence to antipsychotic medication. ${ }^{22}$ The few reviews available on this subject have focused almost entirely on hospitalization costs. ${ }^{19,20,23}$ As such, the purpose of the systematic review reported here was to gather evidence on the economic impact of patients with schizophrenia's nonadherence to antipsychotic medication, focusing on studies that included the analysis of nonadherence and costs among their primary objectives. In addition to hospitalization costs, other cost components were also considered in this review.

\section{Methods}

\section{Objectives and procedures}

The objective of this review was to evaluate the economic consequences of nonadherence to antipsychotic medication in patients with schizophrenia in terms of resource utilization and health care costs. Studies that provided measures of adherence to antipsychotic medication of patients with schizophrenia, health care resource utilization, and costs were gathered to address this objective. This report was developed in accordance with the framework proposed in the Preferred Reporting Items for Systematic reviews and Meta-Analyses (PRISMA) statement. ${ }^{24}$

\section{Eligibility criteria}

Original research published in peer-reviewed journals, in English or Spanish, was checked. The review included studies that met all of the following four criteria: (1) the involvement of patients with declared diagnoses of schizophrenia or schizoaffective disorders, (2) the use of original data as opposed to data from previous publications (reviews were excluded), (3) the provision of direct or indirect measures of adherence, and (4) the provision of comparative information on costs between adherent and nonadherent patients with schizophrenia or schizoaffective disorders. The review excluded studies that provided comparative economic outcomes based on simulation modeling and not on real world data. We used these eligibility criteria to obtain empirical and explicit information on adherence measurements and health care costs simultaneously from the same studies.

\section{Literature search and study selection}

Relevant reports were identified through thorough literature searches of computerized databases including PubMed MEDLINE, Embase, PsychINFO, and BIOSIS (1990 to January 2012) as well as EBMR (2005 to 2011). Key search terms included "schizophrenia," "nonadherence"/"nonadherence," "noncompliance"/"non-compliance," "cost," "pharmacoeconomic," "resource," "economic," "depot," and "long-acting." Several combinations of these keywords joined by the Boolean operators "and" or "or" were used in searches. In addition, the bibliographies of selected articles were reviewed to identify further reports. Previous reviews were not included, but their bibliographies were checked to ensure relevant reports were not overlooked.

\section{Data collection}

A structured form was prepared to gather information on the objectives, methodology, parameters and outcomes evaluated, and results of each study. Studies were coded by author and year of publication, objectives, design, total number of patients evaluated, and outcomes. The design of observational studies was classified as either cross-sectional, cohort (retrospective or prospective), or case-control. Mirror-image designs were frequent and were categorized as such. The quality of the studies was graded according to the STROBE Statement. The STROBE checklist was fulfilled for each of the reports included in the review (all studies were observational), and the 
number of items met was provided as an objective measure of reporting study quality.

\section{Data synthesis and reporting}

A descriptive summary of the results obtained in the studies is provided. Formal meta-analyses were not performed for several reasons; the paucity and heterogeneity of quantitative measures of nonadherence and cost estimates between studies particularly stand out.

\section{Results}

A total of 1148 records were initially retrieved (1100 from the database search and 48 through the bibliographies of selected studies). After discarding duplicates, 640 reports remained, 525 of which were excluded because of noncompliance with the selection criteria after reviewing the title or the abstract. Screening of the remaining 115 reports, either by reviewing the abstract or the full text, led to elimination of 66 more because of the reasons provided in Figure 1. Finally, 41 full-text reports were excluded (Figure 1), leaving eight studies, published between 2000 and 2011, that were included in the review.

Among the selected reports, five were case-series studies, two were mirror-image studies, and one was a cross-sectional study. All of them used data collated retrospectively from

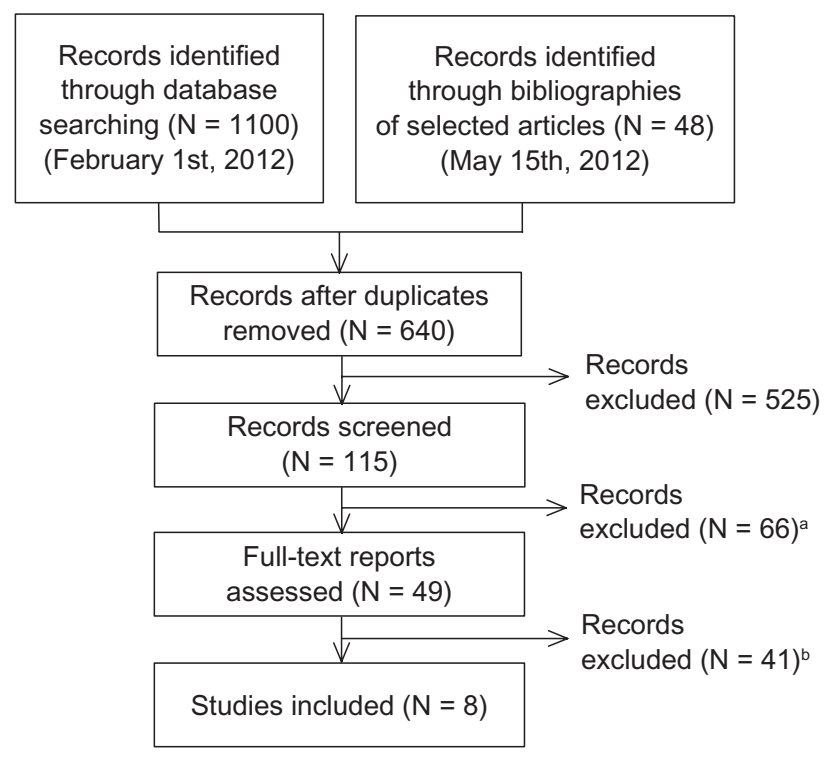

Figure I Flow diagram of the different phases of information retrieval.

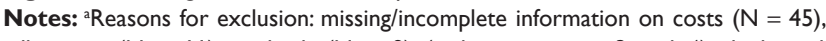
adherence $(\mathrm{N}=\mathrm{II})$, or both $(\mathrm{N}=9)$ (inclusion criteria 3 and 4); duplicated publication $(\mathrm{N}=\mathrm{I})$ (inclusion criterion 2); breasons for exclusion: comparative cost information between adherent and nonadherent patients not provided $(\mathrm{N}=19)$ (inclusion criterion 4); cost-effectiveness or based on simulated data $(N=16)$ (exclusion criterion); review of other studies $(\mathrm{N}=3)$, duplicated publication $(\mathrm{N}=2)$ (inclusion criterion 2); cost information not segregated for patients with schizophrenia $(\mathrm{N}=\mathrm{I})$. various databases; none provided estimations of indirect costs. The studies included in the review met from 12 to 19 of the 22 items of the STROBE checklist. The retrospective medical record reviews featured large sample sizes, ranging from 619 to 35,815 patients. The sample sizes of the two mirror-image studies were of 147 and 443 patients. Six studies were performed in USA, one in the UK, and one in New Zealand. Table 1 provides an overview of the objectives, design, methods, and outcomes on a per-study basis.

The most recently published study featured a comprehensive evaluation of overall direct health care costs under a mirror-image design. ${ }^{25}$ The authors compared the adherence, defined in terms of medication possession ratio (the proportion of days the patient is in possession of any antipsychotic during each 180-day observation period) and the overall costs from the 6 months preceding the initiation of a long-acting antipsychotic to the 6 months following. Together with a significant enhancement of the medication possession ratio from $36.8 \%$ to $60.0 \%$, the mean overall cost declined significantly from US\$11,111.30 to US\$7883.80 per patient, mainly driven by the reduction of hospitalization costs.

Another mirror-image evaluation of patients starting long-acting risperidone was performed in New Zealand. ${ }^{26}$ Compared with the pre long-acting risperidone period, the mean number of admissions for the total study population decreased in the subsequent year (1.38 vs 0.61). However, the mean length of bed stay increased (37.2 vs 53.3 days), as did compulsory treatment use. Different methods were used to estimate hospital costs associated with the use of long-acting risperidone (cost estimates were influenced by the method used). Hospitalization costs decreased by approximately NZ\$1.7 million in the post long-acting risperidone period when computed using a cost-per-admission approach, but an increase of NZ\$3.5 million was observed when a daily hospitalization cost was applied. The authors analyzed the patients who remained on long-acting risperidone 12 months after initiation (58.3\%) separately from those who "discontinued" - defined as any break in which three or more injections were not administered continuously - the drug over a 1-year period after treatment initiation (41.7\%). Cost increase was significantly lower in patients who continued than in those who discontinued long-acting risperidone. In fact, the reduction in hospital admission rates between the two treatment periods was significantly greater in the continuation group, and the mean difference in length of hospital stays between the two treatment periods was also significantly lower for continuers (5.4 vs 31.1 days). 


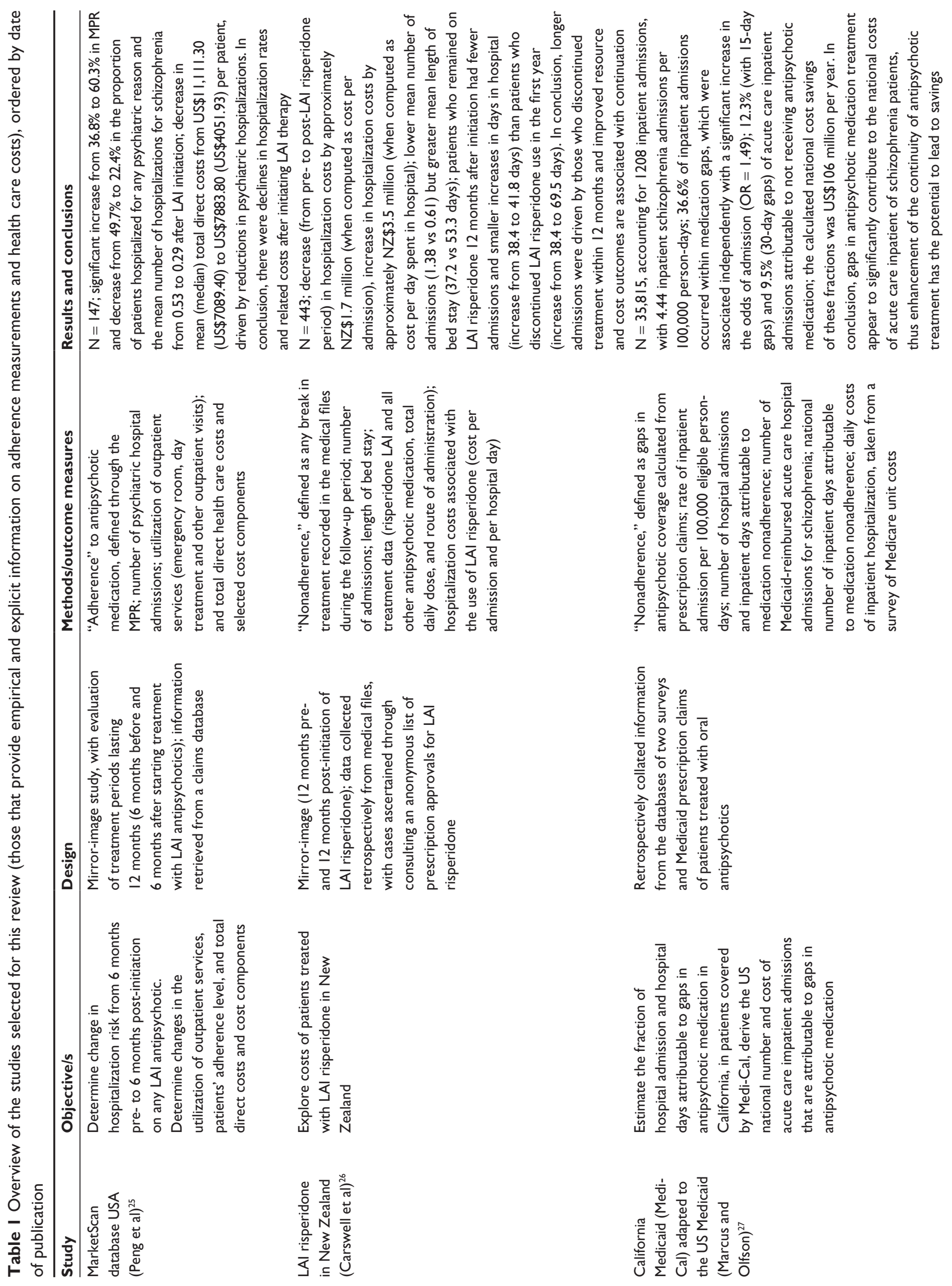




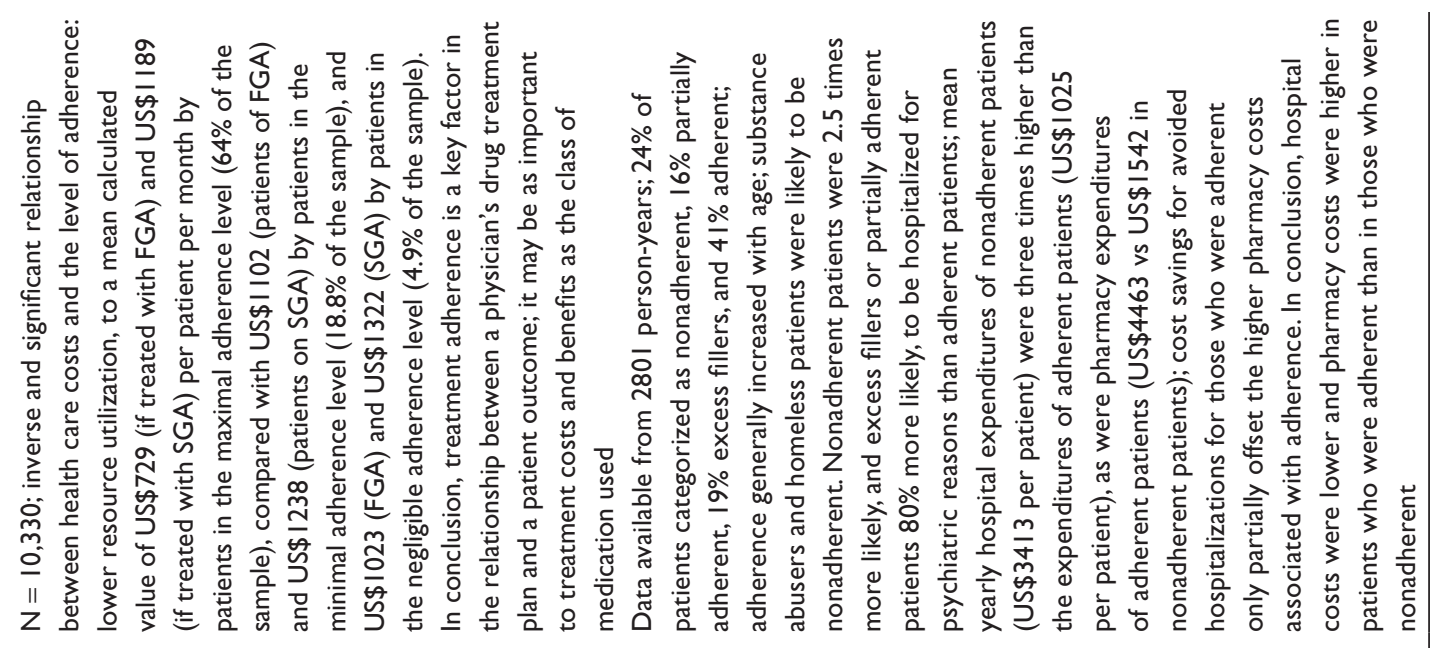
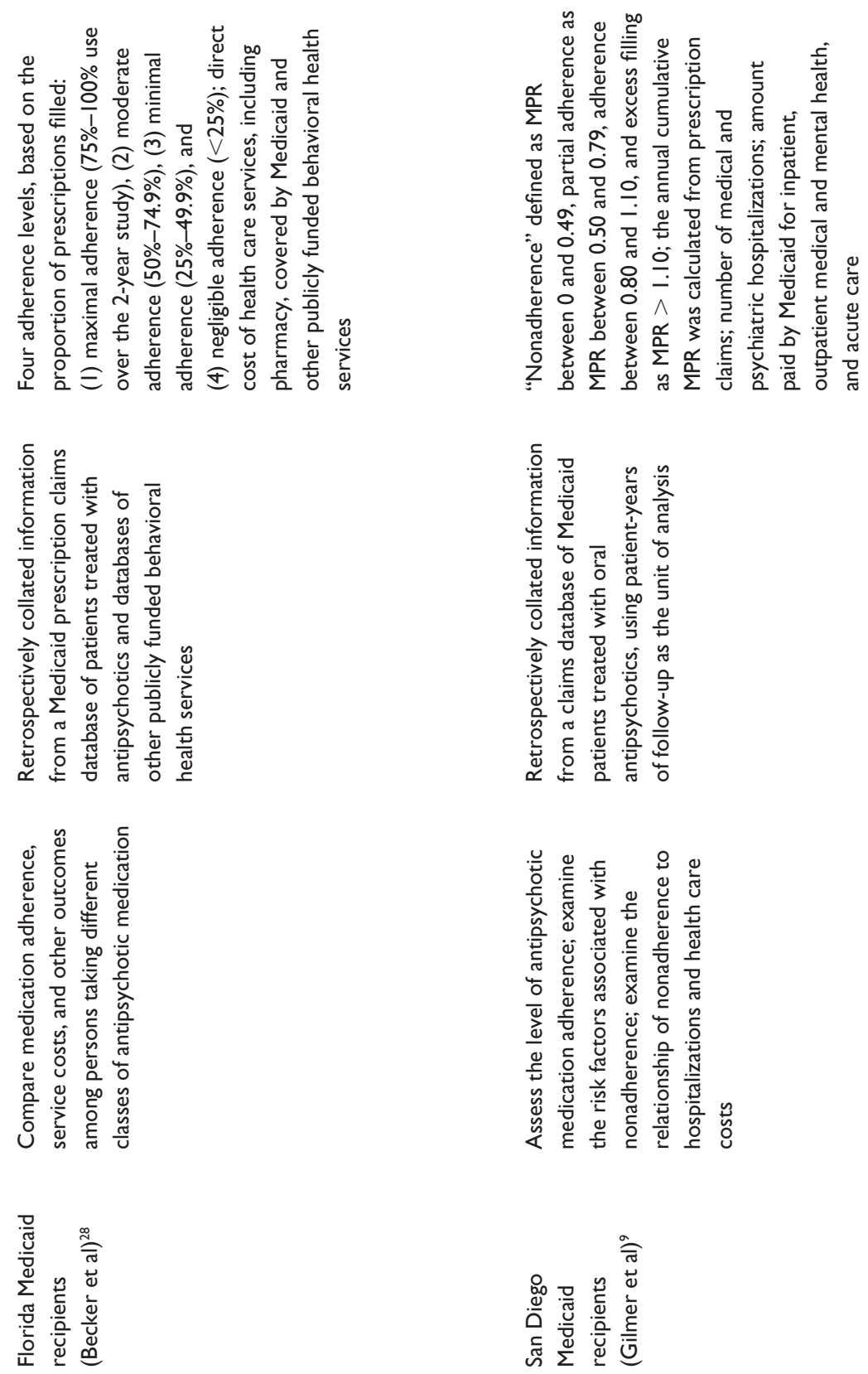


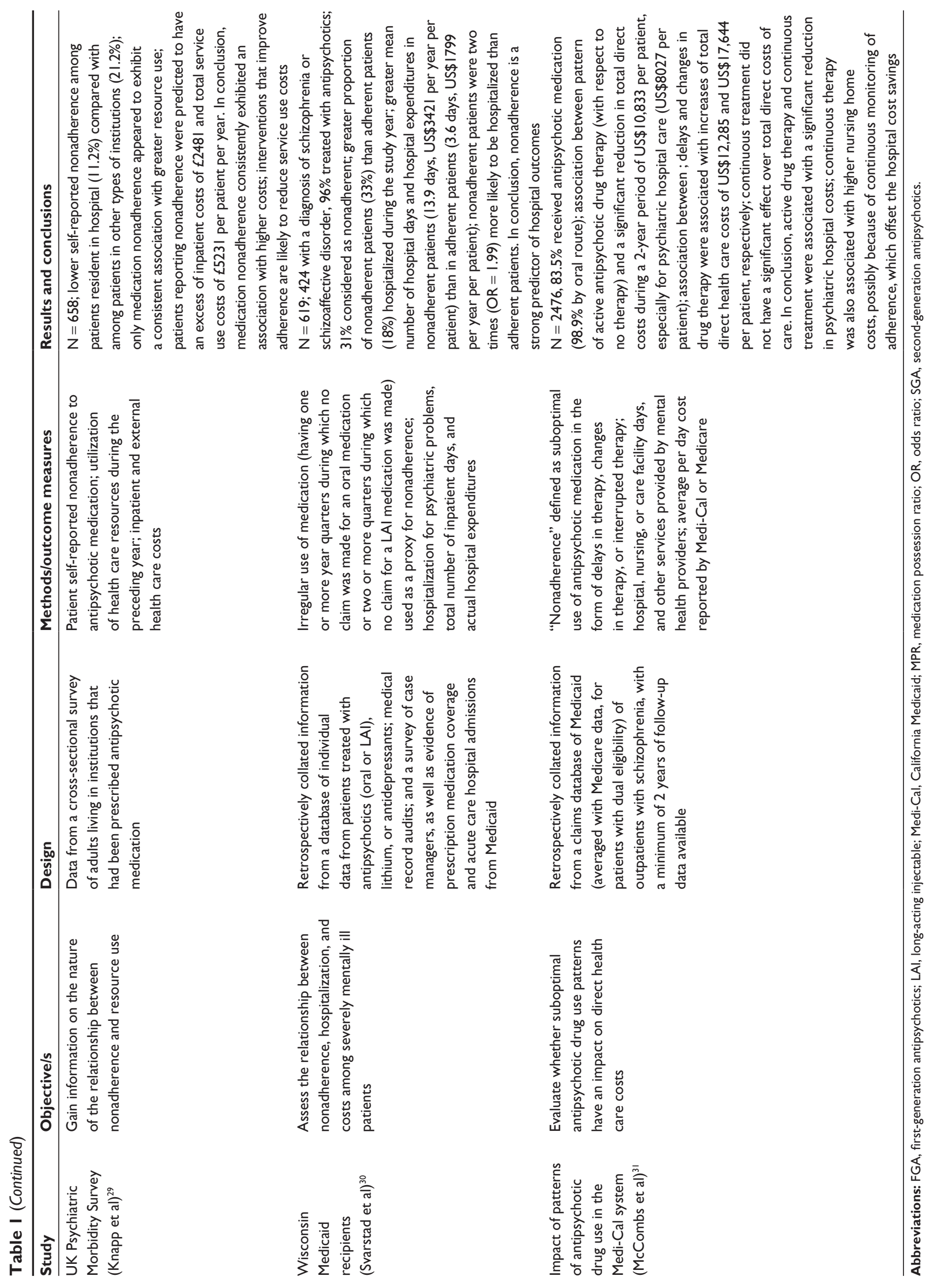


Marcus and Olfson ${ }^{27}$ estimated, by means of econometric analyses of data from California Medicaid files, that improving adherence to eliminate short antipsychotic medication gaps ( $\leq 15$ days) could lower the number of acute care inpatient admissions ( $\leq 30$ days) by approximately $12.3 \%$ and reduce the number of inpatient treatment days by approximately $13.1 \%$, resulting in annual savings of approximately US\$106 million (US\$ adjusted to year 2005) in inpatient care costs for the national Medicaid system. ${ }^{27}$

Becker et a ${ }^{28}$ evaluated 24-month data from Medicaid and public behavioral service system databases in a single US state. They classified patients into four levels of adherence and compared the monthly average overall direct health care costs. Their analysis revealed a significant, inverse relationship between adherence and health care costs. The cost difference between adherent and nonadherent patients was greater among those treated with first-generation than among those treated with second-generation antipsychotics.

The research by Gilmer et al, ${ }^{9}$ also among Medicaid beneficiaries in a single US state, confirmed that nonadherent patients pose much higher hospital costs than adherent patients. This was the sole study we reviewed that evaluated several forms of nonadherence defined in terms of the medication possession ratio, including excess filling of medications. Excess fillers, possibly due to actual overuse and loss or theft of medications, posed higher economic burdens than any other patients. This study found drug acquisition costs were higher for those more adherent to their medication and even higher for excess fillers. Moreover, nonadherent patients were 2.5 times more likely to be hospitalized for psychiatric reasons than adherent patients. Overall cost savings for avoided hospitalizations only partially offset the higher drug acquisition costs associated with adherence. Mean yearly costs for adherent patients (US\$9505) were US\$102 and US\$1337 higher than the costs for those who were partially adherent and nonadherent, respectively.

In the UK study, the authors used data from a public health survey to evaluate the adherence, based on self-report, and outcomes of patients living in institutions who received antipsychotic medications $(72.0 \%$ of those resident in hospitals and $63.3 \%$ of those living in other institutions with a diagnosis of schizophrenia). ${ }^{29}$ In a model that evaluated the influence of various factors on total direct health care costs, nonadherence was associated with an excess of predicted inpatient hospital care and overall health care costs of $£ 2481$ and $£ 5231$ per patient per year, respectively.

Another study, restricted to Medicaid beneficiaries in a single US state that only evaluated hospitalization costs, ${ }^{30}$ reported higher hospitalization costs over 1 year for patients who were irregular users of medication (US\$3421) than for patients who filled medication claims regularly (US\$1799).

Finally, the study by $\mathrm{McCombs}$ et $\mathrm{l}^{31}$ featured an evaluation of overall direct health care costs over patients with dual eligibility (Medicaid and Medicare), of whom just 1.1\% were being treated with second-generation antipsychotics. The authors evaluated the effects of suboptimal antipsychotic drug use over costs. Compared to the costs associated with other patterns of use, delays in drug therapy were associated with a significant increase in mean total costs of US $\$ 12,285$ per patient, while continuous treatment with an antipsychotic drug over 2 years (only $3.2 \%$ of treated patients) did not have a significant effect on the direct health care costs.

\section{Discussion}

Despite the varied study designs, adherence measures, and costs considered in the analyses across studies, the results of the systematic review reported here support that poor adherence to antipsychotic treatment was linked to increased hospitalization rates and resource utilization which resulted in increased direct health care costs.

Hospitalization was found to be less frequent in adherent rather than in nonadherent patients, and related costs were lower. Likewise, nonadherent patients consistently required more treatment interventions for relapses than their adherent counterparts. Based on the review results, adherence was associated with lower costs in six of the eight studies; ${ }^{25-30}$ and with higher costs in the remaining two. ${ }^{9,31}$ Reduced hospitalization rates in adherent patients accounted for a reduction in costs for psychiatric inpatient care in three of the eight studies included in this review, which were focused exclusively on hospitalization costs. ${ }^{26,27,30}$ In one of these studies, longer admissions were driven by treatment discontinuers and treatment continuation was associated with improved resource and cost outcomes compared with treatment discontinuation. ${ }^{26}$ Three studies found a reduction in overall direct health care costs,,$^{25,28,29}$ conflicting with another two studies that showed an increase. ${ }^{9,31} \mathrm{An}$ increase in total costs was observed since expenditures for drug acquisition or adherence-enhancing treatments were slightly higher than savings accrued due to improved adherence. ${ }^{9,31}$

To the knowledge of the authors, this is the first review that has comprehensively evaluated the economic consequences of nonadherence, including - insofar as is possible - components of health care costs, without a preference for the costs of hospitalization. Prior evidence supports that poor treatment adherence leading to relapses 
of schizophrenic symptoms results in high costs of direct health care services. ${ }^{20}$ Most direct health care costs related to this mental illness are attributable to hospitalization for initial episodes and subsequent relapses. ${ }^{20}$ In addition to increasing inpatient care costs, repeated relapses may cause patients, family, and caregivers to become increasingly discouraged and pessimistic about the course of illness, ${ }^{9}$ which may produce secondary consequences of nonadherence: neurological deterioration, ${ }^{32}$ comorbid illness progression, ${ }^{33}$ substance use, ${ }^{34}$ criminal behavior, ${ }^{35}$ suicide attempts, ${ }^{36}$ rehospitalization, ${ }^{23,37}$ or homelessness. ${ }^{38}$

A similar study carried out by Sun et $\mathrm{al}^{19}$ reported that all studies reviewed showed antipsychotic nonadherence was associated with an increase in hospitalization rate, hospital days, or hospital costs. As an example of how differences in methodology or cost components analyzed may affect cost outcomes, Sun et al calculated the US national re-hospitalization costs due to antipsychotic nonadherence using the data from two studies included in this review at US\$1400 million per year. ${ }^{19}$ Such costs were much higher than those estimated by Marcus and Olfson (US\$106 million), ${ }^{27}$ but these authors only considered acute inpatient hospital care costs attributable to gaps in antipsychotic medications of up to 30 days. The latter authors did not include other cost components, longer medication gaps, or other patterns of nonadherence in their analysis.

Although improved adherence to antipsychotic medication may not represent a substantial cost reduction in the short term, as some of the studies reviewed might suggest, ${ }^{9,31}$ investing resources in adherence and reinsertion programs might be more beneficial, from a societal perspective, than investing them in treating preventable relapses.

An important aspect that was not addressed in the studies reviewed relates to the impact of nonadherence on other outcomes, such as employment, quality of life, and, ultimately, the indirect costs associated with schizophrenia. The scarce data available suggest that indirect costs may pose an economic burden comparable to that of direct health care costs. For example, productivity loss may account for more than half of all excess annual costs of patients with schizophrenia. ${ }^{17}$ The resulting picture of the economic impact of nonadherence to antipsychotic medication in these patients may not ultimately be complete until indirect costs are accounted for as well. Presumably, improved adherence could reduce them considerably and thus lower the global economic burden. To advance in this direction, adherence to antipsychotic medication; use of non-pharmacological therapies; and patient-reported outcomes, such as quality of life, should be routinely included in the clinical research of schizophrenia in the future.

\section{Limitations}

When interpreting the results of this review, some limitations should be taken into account. Of note, none of the studies reviewed collected data prospectively. Other limitations concern the aforementioned difficulties inherent in measuring adherence. For example, some studies used patients' self-reports or physicians' reports, which tend to overestimate adherence, and others used prescription claims that are only a proxy for adherence. ${ }^{3}$ Further, the effects of nonadherence should also be evaluated in stable patients on prolonged symptomatic remission who may be engaged in recovery-oriented therapies, and these studies should account, as well, for indirect costs. In addition, most of the data come from the USA and, particularly, from Medicaid services, which may not represent other countries or health service systems. Some studies used a mirror-image design, which has been criticized because of selection bias and artifacts created by variables changing between the control and the test periods. ${ }^{39}$ Finally, at the review level, publication bias could not be quantified because the data was analyzed qualitatively.

\section{Conclusion}

Evidence in the literature supports that nonadherence to antipsychotic medication results in poor health and economic outcomes for patients with schizophrenia. In this systematic review, nonadherence to antipsychotic medication was found to be associated with increased hospitalization rates and resource utilization, which resulted in increased direct health care costs. Investing resources on interventions aimed at improving adherence should be endorsed due to the beneficial effect on patient health without a substantial increase in health care costs. Future studies should evaluate the economic aspects of adherence to antipsychotic medication in stable patients and strive to provide long-term estimations of the indirect costs, in addition to the direct costs, resulting from schizophrenia.

\section{Acknowledgment}

The authors acknowledge the contribution made by Jesus Villoria (medical writer, Medicxact, SL) in the preparation of this manuscript. 


\section{Disclosure}

Tatiana Dilla, Antonio Ciudad, and María Álvarez are full-time employees of Lilly, SA, an affiliate of Eli Lilly and Company. The research reported here was funded by Lilly, SA.

\section{References}

1. World Health Organization. Adherence to Long-Term Therapies: Evidence for Action. Geneva: World Health Organization; 2003.

2. Mueser KT, McGurk SR. Schizophrenia. Lancet. 2004;363(9426): 2063-2072.

3. Lacro JP, Dunn LB, Dolder CR, Leckband SG, Jeste DV. Prevalence of and risk factors for medication nonadherence in patients with schizophrenia: a comprehensive review of recent literature. $J$ Clin Psychiatry. 2002;63(10):892-909.

4. Weiden PJ. Understanding and addressing adherence issues in schizophrenia: from theory to practice. J Clin Psychiatry. 2007;68 Suppl 14 $14-19$.

5. Velligan DI, Wang M, Diamond P, et al. Relationships among subjective and objective measures of adherence to oral antipsychotic medications. Psychiatr Serv. 2007;58(9):1187-1192.

6. Cramer JA, Rosenheck R. Compliance with medication regimens for mental and physical disorders. Psychiatr Serv. 1998;49(2):196-201.

7. Velligan DI, Lam YW, Glahn DC, et al. Defining and assessing adherence to oral antipsychotics: a review of the literature. Schizophr Bull. 2006;32(4):724-742.

8. Leucht S, Heres S. Epidemiology, clinical consequences, and psychosocial treatment of nonadherence in schizophrenia. $J$ Clin Psychiatry. 2006;67 Suppl 5:3-8.

9. Gilmer TP, Dolder CR, Lacro JP, et al. Adherence to treatment with antipsychotic medication and health care costs among Medicaid beneficiaries with schizophrenia. Am J Psychiatry. 2004;161(4): 692-699.

10. Robinson D, Woerner MG, Alvir JM, et al. Predictors of relapse following response from a first episode of schizophrenia or schizoaffective disorder. Arch Gen Psychiatry. 1999;56(3):241-247.

11. Valenstein M, Copeland LA, Blow FC, et al. Pharmacy data identify poorly adherent patients with schizophrenia at increased risk for admission. Med Care. 2002;40(8):630-639.

12. Weiden PJ, Kozma C, Grogg A, Locklear J. Partial compliance and risk of rehospitalization among California Medicaid patients with schizophrenia. Psychiatr Serv. 2004;55(8):886-891.

13. Ascher-Svanum H, Faries DE, Zhu B, Ernst FR, Swartz MS, Swanson JW. Medication adherence and long-term functional outcomes in the treatment of schizophrenia in usual care. J Clin Psychiatry. 2006;67(3):453-460.

14. Lieberman JA. Neurobiology and the natural history of schizophrenia. $J$ Clin Psychiatry. 2006;67(10):e14.

15. Haro JM, Novick D, Suarez D, Ochoa S, Roca M. Predictors of the course of illness in outpatients with schizophrenia: a prospective three year study. Prog Neuropsychopharmacol Biol Psychiatry. 2008; 32(5):1287-1292.

16. Salize HJ, McCabe R, Bullenkamp J, et al. Cost of treatment of schizophrenia in six European countries. Schizophr Res. 2009;111(1-3): $70-77$.

17. Wu EQ, Birnbaum HG, Shi L, et al. The economic burden of schizophrenia in the United States in 2002. J Clin Psychiatry. 2005;66(9):1122-1129.

18. Ascher-Svanum H, Zhu B, Faries DE, Furiak NM, Montgomery W. Medication adherence levels and differential use of mental-health services in the treatment of schizophrenia. BMC Res Notes. 2009;2:6.
19. Sun SX, Liu GG, Christensen DB, Fu AZ. Review and analysis of hospitalization costs associated with antipsychotic nonadherence in the treatment of schizophrenia in the United States. Curr Med Res Opin. 2007;23(10):2305-2312.

20. Thieda P, Beard S, Richter A, Kane J. An economic review of compliance with medication therapy in the treatment of schizophrenia. Psychiatr Serv. 2003;54(4):508-516.

21. Ascher-Svanum H, Zhu B, Faries DE, et al. The cost of relapse and the predictors of relapse in the treatment of schizophrenia. BMC Psychiatry. 2010;10:2.

22. Hughes DA, Bagust A, Haycox A, Walley T. Accounting for noncompliance in pharmacoeconomic evaluations. Pharmacoeconomics. 2001;19(12):1185-1197.

23. Weiden PJ, Olfson M. Cost of relapse in schizophrenia. Schizophr Bull. 1995;21(3):419-429.

24. Moher D, Liberati A, Tetzlaff J, Altman DG; PRISMA Group. Preferred reporting items for systematic reviews and meta-analyses: the PRISMA statement. PLoS Med. 2009;6(7):e1000097.

25. Peng X, Ascher-Svanum H, Faries D, Conley RR, Schuh KJ. Decline in hospitalization risk and health care cost after initiation of depot antipsychotics in the treatment of schizophrenia. Clinicoecon Outcomes Res. 2011;3:9-14.

26. Carswell C, Wheeler A, Vanderpyl J, Robinson E. Comparative effectiveness of long-acting risperidone in New Zealand: a report of resource utilization and costs in a 12-month mirror-image analysis. Clin Drug Investig. 2010;30(11):777-787.

27. Marcus SC, Olfson M. Outpatient antipsychotic treatment and inpatient costs of schizophrenia. Schizophr Bull. 2008;34(1):173-180.

28. Becker MA, Young MS, Ochshorn E, Diamond RJ. The relationship of antipsychotic medication class and adherence with treatment outcomes and costs for Florida Medicaid beneficiaries with schizophrenia. Adm Policy Ment Health. 2007;34(3):307-314.

29. Knapp M, King D, Pugner K, Lapuerta P. Non-adherence to antipsychotic medication regimens: associations with resource use and costs Br J Psychiatry. 2004;184:509-516.

30. Svarstad BL, Shireman TI, Sweeney JK. Using drug claims data to assess the relationship of medication adherence with hospitalization and costs. Psychiatr Serv. 2001;52(6):805-811.

31. McCombs JS, Luo M, Johnstone BM, Shi L. The use of conventional antipsychotic medications for patients with schizophrenia in a medicaid population: therapeutic and cost outcomes over 2 years. Value Health. 2000;3(3):222-231.

32. Lieberman J, Chakos $\mathrm{M}, \mathrm{Wu} \mathrm{H}$, et al. Longitudinal study of brain morphology in first episode schizophrenia. Biol Psychiatry. 2001;49(6): 487-499.

33. Sokal J, Messias E, Dickerson FB, et al. Comorbidity of medical illnesses among adults with serious mental illness who are receiving community psychiatric services. J Nerv Ment Dis. 2004;192(6):421-427.

34. Regier DA, Farmer ME, Rae DS, et al. Comorbidity of mental disorders with alcohol and other drug abuse. Results from the Epidemiologic Catchment Area (ECA) Study. JAMA. 1990;264(19):2511-2518.

35. Modestin J, Ammann R. Mental disorder and criminality: male schizophrenia. Schizophr Bull. 1996;22(1):69-82.

36. Herings RM, Erkens JA. Increased suicide attempt rate among patients interrupting use of atypical antipsychotics. Pharmacoepidemiol Drug Saf. 2003;12(5):423-424.

37. Misdrahi D, Llorca PM, Lançon C, Bayle FJ. Compliance in schizophrenia: predictive factors, therapeutical considerations and research implications. Encephale. 2002;28(3 Pt 1):266-272. French.

38. Olfson M, Mechanic D, Hansell S, Boyer CA, Walkup J. Prediction of homelessness within three months of discharge among inpatients with schizophrenia. Psychiatr Serv. 1999;50(5):667-673.

39. Hargreaves WA, Shumway M. Pharmacoeconomics of antipsychotic drug therapy. J Clin Psychiatry. 1996;57 Suppl 9:66-76. 


\section{Publish your work in this journal}

Patient Preference and Adherence is an international, peer-reviewed, open access journal focusing on the growing importance of patient preference and adherence throughout the therapeutic continuum. Patient satisfaction, acceptability, quality of life, compliance, persistence and their role in developing new therapeutic modalities and compounds to optimize clinical outcomes for existing disease states are major areas of interest. This journal has been accepted for indexing on PubMed Central. The manuscript management system is completely online and includes a very quick and fair peer-review system. Visit http://www.dovepress.com/ testimonials.php to read real quotes from published authors.

Submit your manuscript here: http://www.dovepress.com/patient-preference-and-adherence-journal 